\title{
Systemic mastocytosis with renal light chain amyloidosis: associated non-mast cell disorder or concurrent disease
}

\author{
Moussab Damlaj ${ }^{1,2,3} \cdot$ Hanadi Ashi $^{4} \cdot$ Fouad Boulos $^{4} \cdot$ Hala Kfoury $^{4} \cdot$ Zaher Chakhachiro $^{4}$ (I)
}

Received: 22 May 2019 / Accepted: 26 July 2019 / Published online: 7 August 2019

(C) Springer-Verlag GmbH Germany, part of Springer Nature 2019

\begin{abstract}
Systemic mastocytosis with an associated hematological neoplasm (SM-AHN) is a rare diagnosis commonly associated with myeloid disorders. Herein, we describe the case of a 53-year-old female diagnosed with systemic mastocytosis (SM) in conjunction with renal light chain amyloidosis (AL) and smoldering myeloma. Although cytokines such as IL-6 may play a role in the proliferation of plasma cells, delays in the diagnosis of SM and paucity of relevant studies cast uncertainty on whether the associated disease is secondary to the mast cells or etiologically independent. To our knowledge, this is the first case of confirmed renal AL disease in conjunction with SM. We review and summarize the available literature describing SM in association with plasma cell disorders.
\end{abstract}

Keywords Systemic mastocytosis · Plasma cell disorder · Amyloidosis

\section{Introduction}

Mastocytosis is a pathologic condition characterized by mast cell proliferation and accumulation in one or more body sites. Cutaneous mastocytosis $(\mathrm{CM})$ refers to exclusive infiltration of the skin by mast cells, whereas extra-cutaneous involvement is equated with systemic mastocytosis (SM) that can be associated with organ dysfunction and shortened life span. Solitary collection of mast cells involving various tissues that do not meet the defining criteria of either $\mathrm{CM}$ or SM can occasionally otherwise occur. Common sites of involvement in SM include the bone marrow, liver, spleen, gastrointestinal tract, and lymph nodes - with or without cutaneous infiltration. Systemic mastocytosis was originally classified as a subgroup within the myeloproliferative neoplasms (MPN);

Zaher Chakhachiro

zc04@aub.edu.lb

1 Division of Hematology \& HSCT, Department of Oncology, King Abdulaziz Medical City, Riyadh, Kingdom of Saudi Arabia

2 King Saud bin Abdulaziz University for Health Sciences, Riyadh, Kingdom of Saudi Arabia

3 King Abdullah International Medical Research Center, Riyadh, Kingdom of Saudi Arabia

4 Department of Pathology and Laboratory Medicine, American University of Beirut, Beirut, Lebanon however, due to its unique features and variable clinical course, it was reclassified as a separate entity [1]. In the 2016 World Health Organization (WHO) revision, SM was divided into five subgroups: indolent, smoldering, systemic with an associated hematological neoplasm (SM-AHN), aggressive, and leukemic. A complete diagnosis requires information on characterizing $\mathrm{B}$ and $\mathrm{C}$ findings [2]. The WHO mandates the presence of one major and one minor criterion, or three minor criteria, for the diagnosis of systemic mastocytosis [3].

The clinical course of SM is variable; patients with indolent or smoldering disease show a better prognosis than those with SM-AHN and mast cell leukemia. Outcome in SM-AHN (previously SM with associated non-mast cell lineage disease) tends to be largely driven by the nature of the associated disease, which is most frequently myeloid and only rarely $(10 \%$ of cases) lymphoid [4]. Herein, we report a rare case of a 53year-old woman with SM-AHN, associated with renal lambda light chain amyloidosis (AL) in conjunction with smoldering multiple myeloma (SMM).

\section{Case report}

A 53-year-old woman with a history of papillary thyroid cancer presented to the American University of Beirut Medical Center (AUBMC) with mild peripheral swelling. Her physical 
examination was unremarkable with the exception of mild lower extremity edema and a palpable left neck mass attributable to her known thyroid disease. The patient reported no other significant past medical history and was a non-smoker. Family history was negative for malignancies. Laboratory investigations showed normal complete blood count (CBC), electrolyte, renal, and liver enzyme panels. Coagulation studies were normal. Lactate dehydrogenase (LDH) was elevated at $403 \mathrm{IU} / \mathrm{L}$, and 24-h urine collection showed proteinuria of $0.89 \mathrm{~g} / \mathrm{L}$. Free light chain assessment showed an elevated lambda free light chain at $52.1 \mathrm{mg} / \mathrm{L}$ with a kappa/lambda ratio of 0.18 . Serum protein electrophoresis (SPEP) and immunofixation (IF) showed evidence of heavy chain IgG lambda subtype at $7.1 \mathrm{~g} / \mathrm{L}$. Urine protein electrophoresis (UPEP) and IF confirmed the presence of lambda light chain. Initial bone marrow aspirate showed patchy atypical plasma cells accounting for $9 \%$ of marrow cellularity. Fluorescence in situ hybridization (FISH) evaluation for $17 \mathrm{p}$ and $13 \mathrm{q}$ deletion as well as IGH-FGFR3 rearrangement was negative. No renal biopsy was pursued at the time and a definitive diagnosis of a plasma cell neoplasia (PCN) causing end-organ damage could not be established.

Follow-up after 6 months with repeat 24-h urine collection showed progressive proteinuria now meeting nephrotic range criteria at $3.42 \mathrm{~g} / 24 \mathrm{~h}$, in addition to albuminuria at $2.7 \mathrm{~g} / 24 \mathrm{~h}$. Renal function remained normal. At this time, renal biopsy was performed and showed glomeruli with variable mesangial expansion by pink amorphous material with minimal hypercellularity (Fig. 1). Staining for Congo red was positive in the vessel walls and to a lesser extent within the glomeruli (Fig. 1b). Immunofluorescence showed positivity for immunoglobulin lambda light chain in the perivascular and interstitial spaces, and within glomeruli. A diagnosis of light chain amyloidosis with renal involvement was therefore rendered. An abdominal ultrasound showed evidence of hepatomegaly at $22 \mathrm{~cm}$ without splenomegaly. $\mathrm{CBC}$ with differential, liver enzymes and coagulation profile remained normal. The patient did not have clinical signs of portal hypertension. Positron emission tomography with computed tomography (PET/CT) showed normal skeletal and extra-skeletal metabolic activity. Repeat bone marrow assessment with aspirate and biopsy showed a $30 \%$ population of clonal, lambda monotypic plasma cells, in a $40 \%$ normocellular marrow (Fig. 2a, b). Additionally, several paratrabecular and interstitial aggregates of atypical spindle-shaped mast cells were noted. The mast cells stained positive for CD117 and CD25 (Fig. 3a-d). Congo red staining of the bone marrow was negative. Mutation analysis for KIT and serum tryptase level was not done. Further inquiry did not reveal systemic manifestations of mastocytosis, except for a remote history of pruritus and skin lesions that were clinically thought to be insect biterelated. The overall presentation was therefore compatible with SM-AHN, the associated hematological neoplasm being smoldering myeloma associated with renal light chain amyloidosis (AL). The patient was not treated and was subsequently lost to follow-up.

\section{Discussion}

SM is a heterogeneous disease with several subtypes and variable prognosis. SM-AHN is associated with multifocal aggregates of spindle-shaped mast cells observed in conjunction with another hematologic neoplasm diagnosed before, at the same time, or after SM, as defined by the WHO criteria. The associated disease is most commonly of myeloid origin, but can in a minority of cases be of lymphoid or plasma cell origin [5]. Pardanani et al. examined 138 consecutive patients with SM-AHN at the Mayo Clinic and reported that among them, $123(89 \%)$ had an associated myeloid neoplasm, 7 (5\%) had lymphoma, $6(4 \%)$ had plasma cell dyscrasia, and the remaining $2(2 \%)$ had chronic lymphocytic leukemia [6]. Horny et al. noted that SM is a rare disease that was found in only in about $0.3 \%$ of the 19,500 marrow samples submitted for evaluation and that SM-AHN, represented around one-third of all cases of SM, making it the second most frequent subtype; however, it was never included in the clinical differential diagnosis [7]. Again, myeloid neoplasm represented $90 \%$ of the associated diseases in Horny's series. It is important to highlight that SMAHN was not suspected in any of the cases, highlighting the
Fig. 1 a Renal biopsy showing variable deposition of pink amorphous material (Hematoxylin-eosin stain, $\times 400$ magnification). b Under polarized light there is apple green birefringence consistent with amyloid (Congo red stain, $\times 400$ magnification)

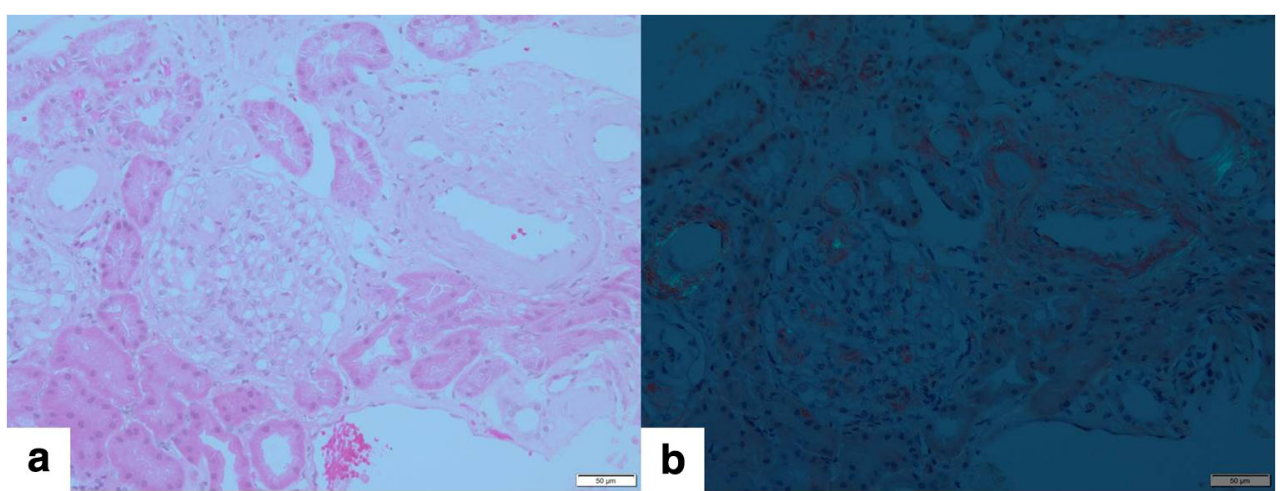


Fig. 2 a Bone marrow biopsy showing increased plasma cells (immunohistochemical stain for CD38, $\times 500$ magnification). $\mathbf{b}$ Bone marrow biopsy showing monotypic expression of lambda light chain in plasma cells (immunohistochemical staining for lambda immunoglobulin light chain, $\times 500$ magnification). c Bone marrow biopsy showing lack of expression of kappa light chain in plasma cells

(immunohistochemical staining for kappa immunoglobulin light chain, $\times 500$ magnification)

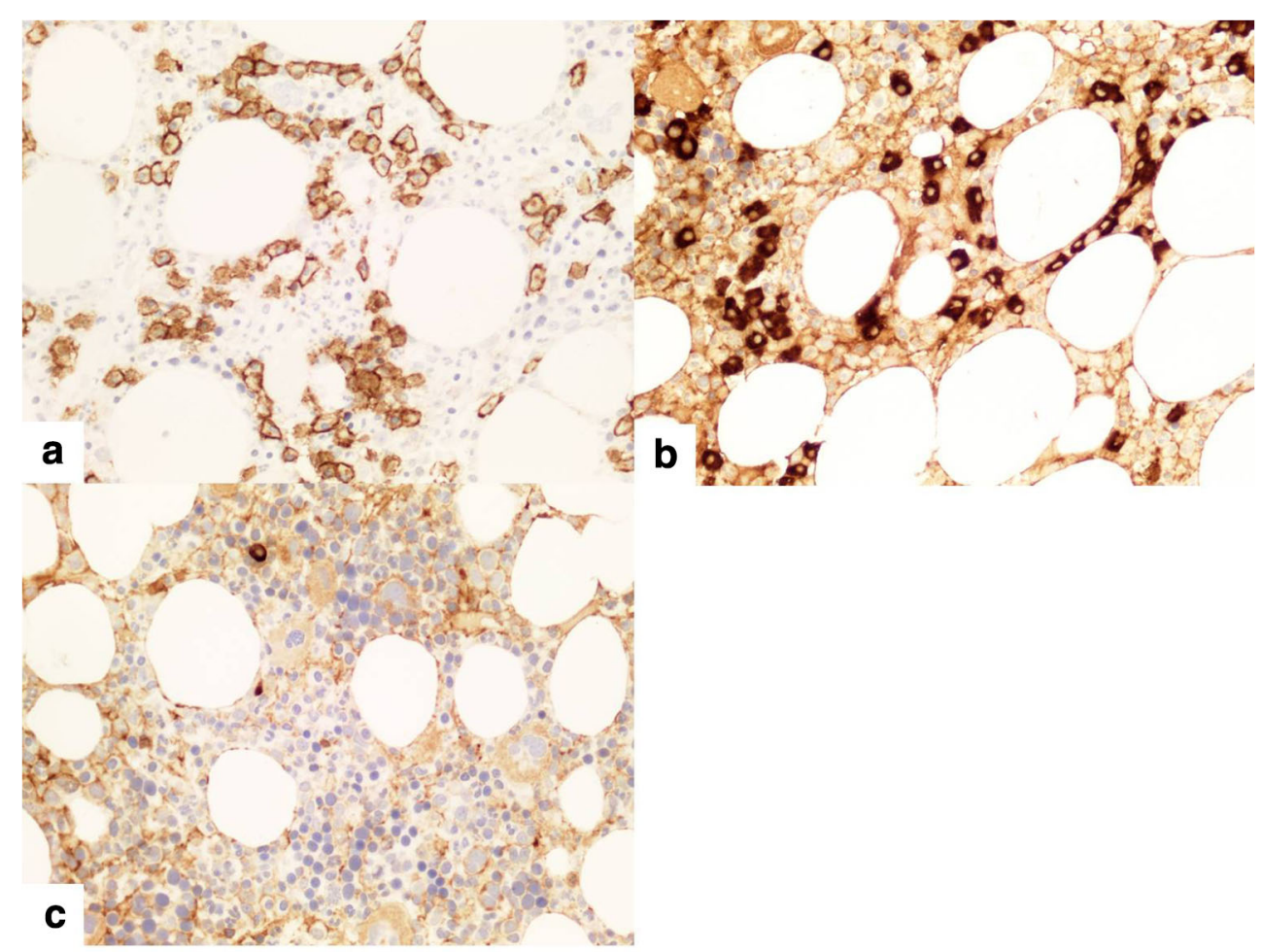

critical role of thorough pathological review and the likely under-diagnosis of this finding.

Collectively, there is a paucity of reported cases of PCN associated with SM in the literature. As shown in Table 1, we identified a total of 12 cases of SM diagnosed before, after, or simultaneously with a PCN. Eight cases were diagnosed simultaneously where the associated PCN either monoclonal gammopathy of unknown significance (MGUS), smoldering multiple myeloma (SMM), or plasma cell myeloma (PCM) [8-15]. On the other hand, SM preceded light chain deposition
Fig. 3 a Bone marrow aspirate showing the presence of spindleshaped mast cells (WrightGiemsa stain, $\times 1000$

magnification). b Bone marrow biopsy showing large aggregates of paratrabecular spindle-shaped mast cells (Hematoxylin and Eosin stain $\times 400$ magnification). c Bone marrow biopsy showing CD117 expression in the mast cells (immunohistochemical staining for CD117, $\times 500$ magnification). $\mathbf{d}$ Bone marrow biopsy showing CD25 expression in the atypical mast cells (immunohistochemical staining for CD25, $\times 500$ magnification)

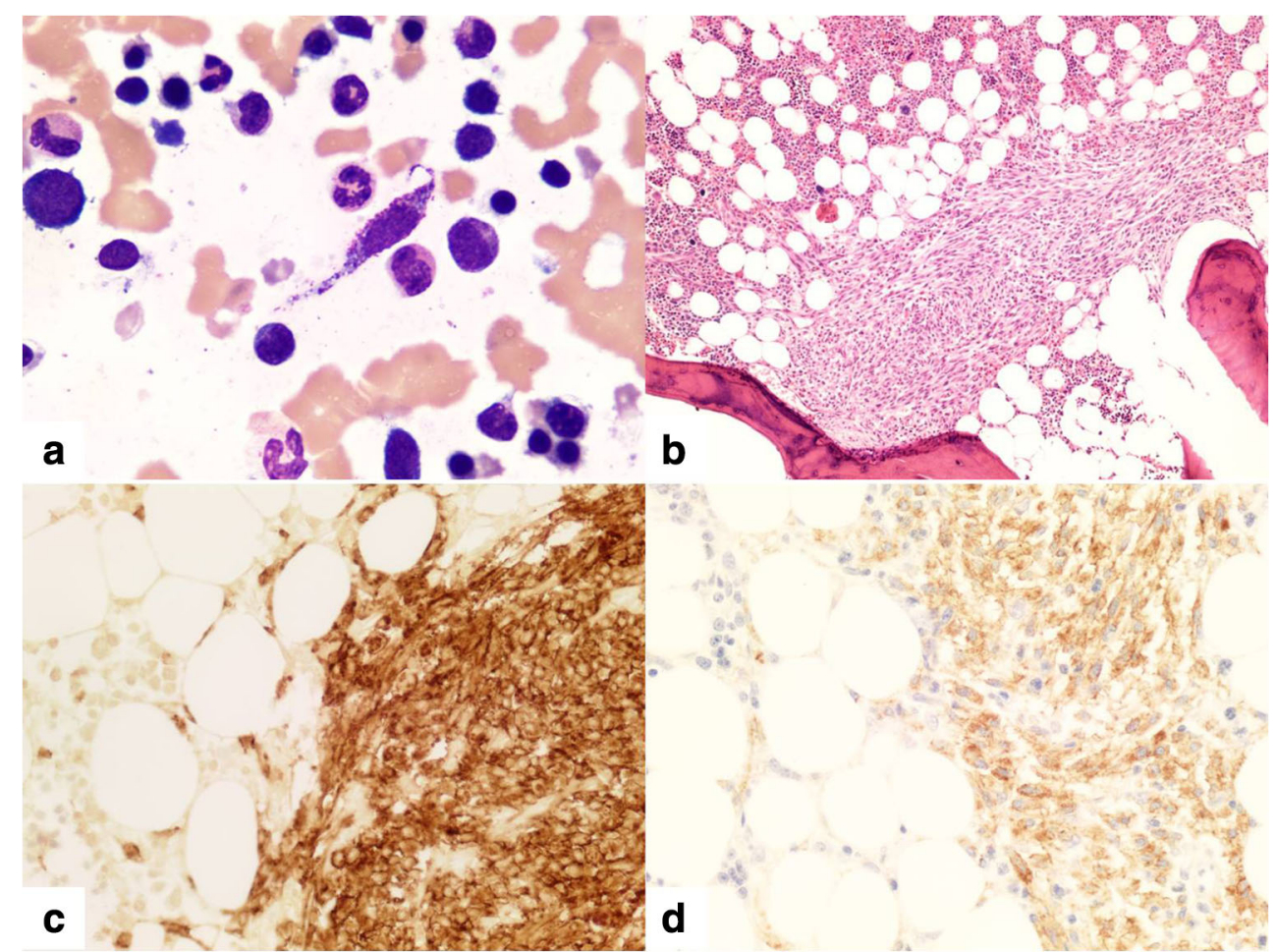




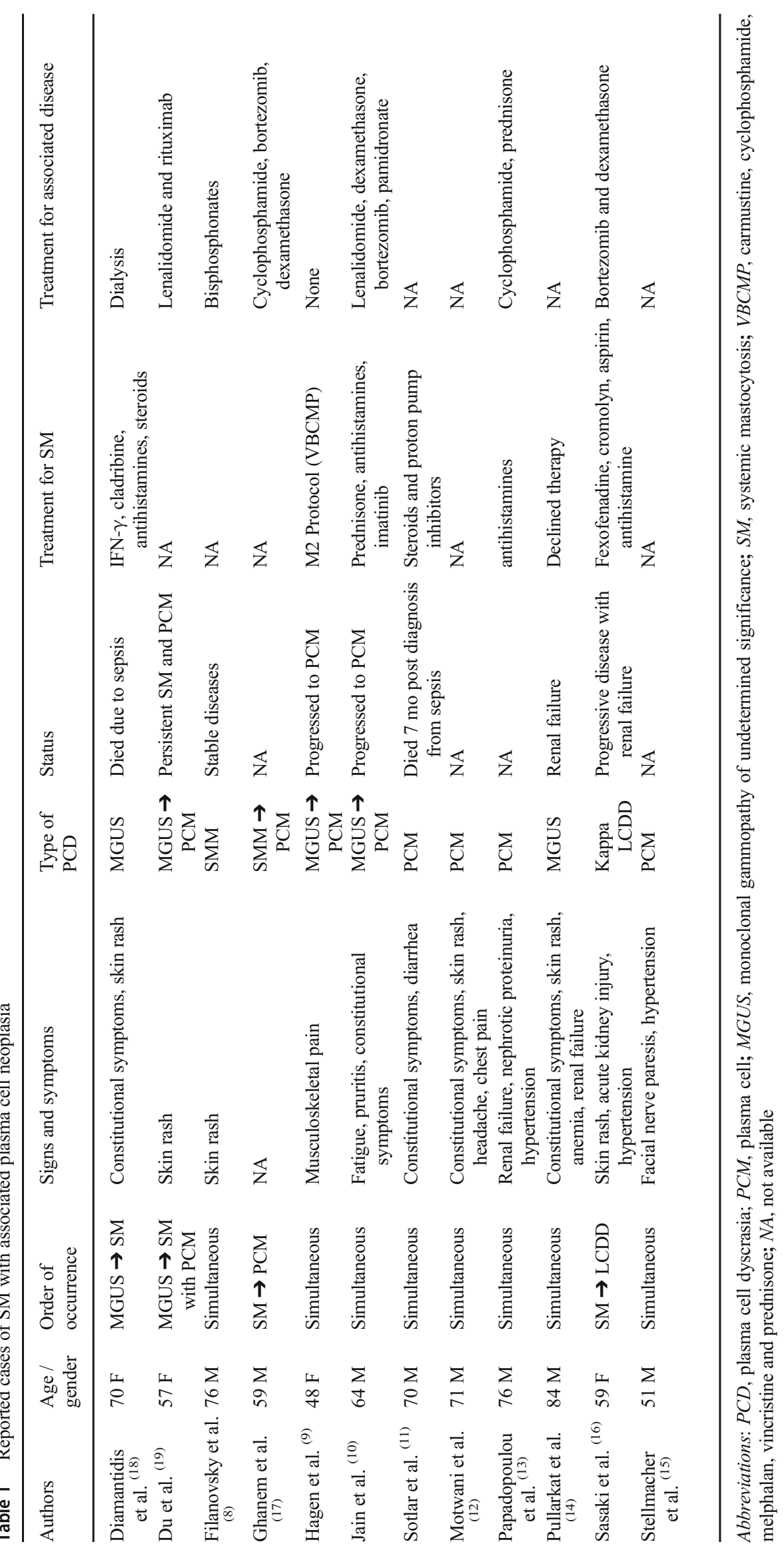


disease (LCDD) or PCM in two cases [16, 17], while MGUS preceded SM in the remaining two cases $[18,19]$. Prior literature has hypothesized that mast cells play a role in the proliferation of malignant lymphocytes. This potential was demonstrated in Waldenstron's macroglobulinemia, Hodgkin lymphoma, and PCM, possibly through IL-6 and stem cell factor which can induce plasma cell proliferation [20-23]. Given that the reported literature on PCN in conjunction with SM is limited, and the sequence of disease is not uniform as indicated above, it remains unknown whether such in vitro observations hold true in PCD.

Finally, the clinical symptoms of SM and PCN may overlap because of bone involvement, which may lead to bone pain and pathologic fractures in both conditions. In such cases, distinguishing the underlying culprit may not always be evident. In PCM, there is increased osteoclastic activity mediated by both receptor activator of nuclear factor kappa-B ligand (RANKL) and osteoprotegerin (OPG). This ultimately leads to bone resorption and the characteristic lytic lesions seen on various imaging modalities in myeloma cases [24]. On the other hand, SM-associated bone disease is thought to manifest due to the release of various mast cell mediators including histamine, proteases, and heparin among others. These can manifest with a number of skeletal patterns on radiographic studies including osteopenia and osteoporosis, and ranging from lytic to sclerotic changes [25]. Thus, thorough radiographic examination of the pattern of bone disease can help differentiate the underlying cause. Furthermore, while normal and neoplastic mast cells express CD117 (ckit), this marker can be overexpressed in approximately $30 \%$ of myelomas, which may lead to a diagnostic challenge to the pathologist, especially if the mast cells are not spindle-shaped [26].

To conclude, we presented a case that further illustrates the association of SM with myeloid/lymphoid disorders. The patient met diagnostic criteria for SM as she had multifocal bone marrow aggregates of mast cells that exhibited abnormal/ spindle morphology and stained positive for CD25. The case is unique as it is the first to include renal $\mathrm{AL}$ in conjunction with SM. Previously, Papadopoulou et al. reported a case of nephrotic range proteinuria in conjunction with SM, and although amyloidosis was suspected, it was not proven given the heightened risk of renal biopsy in the context of the coagulopathy present at the time [13]. Although it is possible that $\mathrm{AL}$ amyloid was the culprit in that case, other etiologies of nephrotic proteinuria are possible including secondary amyloidosis as reported by Sotlar et al. [11]. It is important to note that the co-existence of PCN and SM may be an underrecognized phenomenon, and the case presented herein sheds further light that the spectrum of PCN can extend to AL disease as well. Further insight may help elucidate the role of mast cells in the proliferative potential of the associated PCN, thus altering the expected disease course and patient outcome.

\section{Compliance with ethical standards}

Conflict of interest The authors declare that they have no conflict of interest.

\section{References}

1. Scherber RM, Borate U (2018) How we diagnose and treat systemic mastocytosis in adults. Br J Haematol 180(1):11-23

2. Arber DA, Orazi A, Hasserjian R, Thiele J, Borowitz MJ, Le Beau MM et al (2016) The 2016 revision to the World Health Organization classification of myeloid neoplasms and acute leukemia. Blood 127(20):2391-2405

3. Pardanani A (2016) Systemic mastocytosis in adults: 2017 update on diagnosis, risk stratification and management. Am J Hematol 91(11):1146-1159

4. Valent P, Sperr WR, Akin C (2010) How I treat patients with advanced systemic mastocytosis. Blood 116(26):5812-5817

5. Stoecker MM, Wang E (2012) Systemic mastocytosis with associated clonal hematologic nonmast cell lineage disease: a clinicopathologic review. Arch Pathol Lab Med 136(7):832-838

6. Pardanani A, Lim KH, Lasho TL, Finke C, McClure RF, Li CY et al (2009) Prognostically relevant breakdown of 123 patients with systemic mastocytosis associated with other myeloid malignancies. Blood 114(18):3769-3772

7. Horny HP, Sotlar K, Sperr WR, Valent P (2004) Systemic mastocytosis with associated clonal haematological non-mast cell lineage diseases: a histopathological challenge. J Clin Pathol 57(6): 604-608

8. Filanovsky K, Lev S, Haran M, Feldberg E, Bassous L, Berrebi A, Shtalrid M (2010) Systemic mastocytosis associated with smoldering multiple myeloma: an unexpected diagnosis in a patient with a rash. Leuk Lymphoma 51(6):1152-1154

9. Hagen W, Schwarzmeier J, Walchshofer S, Zojer N, Chott A, Sillaber C, Ackermann J, Simonitsch I, Bühring HJ, Drach J, Lechner K, Horny HP, Valent P (1998) A case of bone marrow mastocytosis associated with multiple myeloma. Ann Hematol 76(3-4):167-174

10. Jain P, Verstovsek S, Orlowski RZ, Yap E, Amin HM (2012) An unusual case of aggressive systemic mastocytosis with associated refractory plasma cell myeloma. Clin Lymphoma Myeloma Leuk 12(6):459-462

11. Sotlar K, Saeger W, Stellmacher F, Stahmer J, Jackle S, Valent P et al (2006) "Occult" mastocytosis with activating c-kit point mutation evolving into systemic mastocytosis associated with plasma cell myeloma and secondary amyloidosis. J Clin Pathol 59(8):875878

12. Motwani P, Kocoglu M, Lorsbach RB (2009) Systemic mastocytosis in association with plasma cell dyscrasias: report of a case and review of the literature. Leuk Res 33(6):856-859

13. Papadopoulou V, Ioannou S, Levidou G, Variami E, Kouzis P, Siakantaris M (2014) Systemic mastocytosis accompanied by a non-secretory plasma cell dyscrasia and nephrotic syndrome-level proteinuria in a 76-year-old patient. Acta Haematol 131(2):78-83

14. Pullarkat ST, Sedarat F, Paquette R, Said J (2008) Systemic mastocytosis with plasma cell dyscrasia: report of a case. Leuk Res 32(7):1160-1163

15. Stellmacher F, Sotlar K, Balleisen L, Valent P, Horny HP (2004) Bone marrow mastocytosis associated with IgM kappa plasma cell myeloma. Leuk Lymphoma 45(4):801-805

16. Sasaki K, Chang A, Najafian B (2012) Indolent systemic mastocytosis associated with light chain deposition disease. Clin Kidney J 5(5):424-427 
17. Ghanem S, Garcia G, Ying L, Hurford M, Odaimi M (2016) Systemic mastocytosis with smoldering multiple myeloma: report of a case. Case Rep Oncol Med 2016(3161768):1-6

18. Diamantidis MD, Myrou AD, Kaiafa GD, Kaloutsi V, Karayannopoulou G, Theodoridis A, Adamidou A, Papadopoulos A, Grekas D (2011) Aggressive systemic mastocytosis associated with mesangioproliferative glomerulonephritis. Acta Haematol 125(3):153-159

19. Du S, Rashidi HH, Le DT, Kipps TJ, Broome HE, Wang HY (2010) Systemic mastocytosis in association with chronic lymphocytic leukemia and plasma cell myeloma. Int J Clin Exp Pathol 3(4):448457

20. Tournilhac O, Santos DD, Xu L, Kutok J, Tai YT, Le Gouill S et al (2006) Mast cells in Waldenstrom's macroglobulinemia support lymphoplasmacytic cell growth through CD154/CD40 signaling. Ann Oncol 17(8):1275-1282

21. Molin D, Fischer M, Xiang Z, Larsson U, Harvima I, Venge P, Nilsson K, Sundstrom C, Enblad G, Nilsson G (2001) Mast cells express functional CD30 ligand and are the predominant CD30Lpositive cells in Hodgkin's disease. Br J Haematol 114(3):616-623

22. Bataille R, Jourdan M, Zhang XG, Klein B (1989) Serum levels of interleukin 6 , a potent myeloma cell growth factor, as a reflect of disease severity in plasma cell dyscrasias. J Clin Invest 84(6):20082011

23. Lemoli RM, Fortuna A, Grande A, Gamberi B, Bonsi L, Fogli M, Amabile M, Cavo M, Ferrari S, Tura S (1994) Expression and functional role of c-kit ligand (SCF) in human multiple myeloma cells. Br J Haematol 88(4):760-769

24. Hameed A, Brady JJ, Dowling P, Clynes M, O'Gorman P (2014) Bone disease in multiple myeloma: pathophysiology and management. Cancer Growth Metastasis 7:33-42

25. Fritz J, Fishman EK, Carrino JA, Horger MS (2012) Advanced imaging of skeletal manifestations of systemic mastocytosis. Skelet Radiol 41(8):887-897

26. Schmidt-Hieber M, Perez-Andres M, Paiva B, Flores-Montero J, Perez JJ, Gutierrez NC, Vidriales MB, Matarraz S, San Miguel JF, Orfao A (2011) CD117 expression in gammopathies is associated with an altered maturation of the myeloid and lymphoid hematopoietic cell compartments and favorable disease features. Haematologica 96(2):328-332

Publisher's note Springer Nature remains neutral with regard to jurisdictional claims in published maps and institutional affiliations. 